\title{
Kinetics of Corrosion Fatigue Crack Growth in High Strength \\ Low-alloy Steels in $3.5 \% \mathrm{NaCl}$ Aqueous Solution*
}

\author{
By Tetsuya SAITO**
}

\begin{abstract}
Synopsis
Corrosion fatique crack growth rates as a function of the stress intensity factor range were investigated in the $3.5 \% \mathrm{NaCl}$ aqueous solution of various temperatures between $278 K$ and $333 K$ under a constant applied electrochemical potential of $-1050 \mathrm{mV}$ vs. Ag/AgCl reference electrode. Generally speaking, crack growth is enhanced as solution temperature rises. The corrosion fatique crack growth rate-stress intensity factor range curve can be divided into three distinct stages independent of testing temperature; at low $\Delta K$ levels or Range I, corrosion fatigue crack growth rate is strongly dependent on $\Delta K$ and slightly on testing temperature. In the range of moderate $\Delta K$ or Range $I I$, the extent of which depends on testing temperature, the $\Delta K$ dependence of the crack growth rate curves disappears and crack growth rate reaches a limiting value. The apparent activation energy for the rate limit region of Range II was found to be approximately $40.0 \mathrm{~kJ} /$ mole, which can be compared well with that for apparent hydrogen diffusion in steel. At higher $\Delta K$ levels or in Range III, corrosion fatigue crack growth rates coincide with those obtained in ambient laboratory air, indicating that the corrosion fatigue crack growth in this range is not affected essentially by the aqueous environment.
\end{abstract}

\section{Introduction}

It has been generally recognized that aqueous environment enhanced fatigue crack growth is observed in many engineering materials. In particular, high strength steels are highly susceptible to the enhancement of fatigue crack growth in such an environment. The previous paper ${ }^{1)}$ pointed out that the enhancement of fatigue crack growth in synthetic seawater under application of cathodic electrochemical potentials can be attributed to hydrogen-assisted mechanism.

On the other hand, it has been commonly recognized that hydrogen plays a strong role also in the stress corrosion cracking of high strength steels under sustained load in aqueous environment. Many investigations have been carried out on the kinetics of the stress corrosion cracking. ${ }^{2-5}$ ) But for all extensive theoretical and experimental studies on corrosion fatigue behaviors of high strength steels in aqueous environment, few have been reported on the kinetics of corrosion fatigue crack growth.

The objective of the present investigation is, therefore, measuring fatigue crack growth rate in the $3.5 \%$ $\mathrm{NaCl}$ aqueous solution as a function of the cyclic stress intensity factor range, $\Delta K$, and testing temperature. The dependence of crack growth rate on $\Delta K$ is detected in a wide range of $\Delta K$. An attempt will be made to determine whether corrosion fatigue crack growth shows a limiting rate as is the case with stress corrosion cracking of high strength steels under sustained loading, ${ }^{2,6)}$ the existence of which indicates that some rate controlling process is operative. Primary emphasis of the discussion will be then placed on the rate controlling process in this crack growth range in connection with fracture surface morphology of the specimen. The $3.5 \% \mathrm{NaCl}$ aqueous solution was chosen as a controlled environment instead of the synthetic seawater which was used in the previous study ${ }^{1)}$ in order to avoid confusing effects of calcareous deposit formation.

\section{Materials and Experimental Procedures}

\section{Materials}

The materials used in the present experiment were two Ni-Cr-Mo low-alloy steels with 0.18 and $0.2 \mathrm{wt} \% \mathrm{C}$, melted in a vacuum high frequency induction furnace. The chemical compositions of the experimented steels are listed in Table 1. After the steels were forged and hot rolled at $1473 \mathrm{~K}$ into $8.0 \mathrm{~mm}$ thick plates, all the steel plates were austenitized at $1223 \mathrm{~K}$ and water quenched. The tempering treatment was carried out for both steels at $898 \mathrm{~K}$ for $1 \mathrm{hr}$, followed by water quenching, in order to obtain the $0.2 \%$ offset yield strength level of $\sigma_{y} \simeq 1080 \mathrm{MPa}$ or $110 \mathrm{kgf} / \mathrm{mm}^{2}$. The mechanical properties of the experimented steels at room temperature are tabulated in Table 2.

Table 2. Mechanical properties of the steels at room temperature.

\begin{tabular}{c|cccc} 
Steel No. & $\begin{array}{c}0.2 \% \text { offset } \\
\text { strength } \\
(\mathrm{MPa})\end{array}$ & $\begin{array}{c}\text { Tensile } \\
\text { strength } \\
(\mathrm{MPa})\end{array}$ & $\begin{array}{c}\text { Elonga- } \\
\text { tion } \\
(\%)\end{array}$ & $\begin{array}{c}\text { Reduction } \\
\text { in area } \\
(\%)\end{array}$ \\
\hline ST22 & 1080.2 & 1134.1 & 15.6 & 69.0 \\
ST28 & 1072.8 & 1086.6 & 15.0 & 70.7
\end{tabular}

Table 1. Chemical compositions of the steels used. (wt\%)

\begin{tabular}{c|cccccccccccccccccccccc} 
Steel No. & G & Si & Mn & P & S & Ni & Gr & Mo & Gu & V & Ti & Al & B \\
\hline ST22 & 0.20 & 0.54 & 0.80 & 0.004 & $<0.005$ & 1.76 & 0.69 & 0.55 & 0.30 & 0.063 & 0.072 & 0.095 & 0.0016 & 0.0094 \\
ST28 & 0.18 & 0.52 & 0.95 & $<0.002$ & $<0.005$ & 1.52 & 0.25 & 0.60 & 0.30 & 0.062 & 0.10 & 0.048 & - & 0.0023
\end{tabular}

* Based on the paper presented to the 106th ISIJ Meeting, October 1983, S1491, at Akita University in Akita. Manuscript received December 4, 1983 . (C) 1984 ISIJ

** National Research Institute for Metals, Nakameguro, Meguro-ku, Tokyo 153. 


\section{Experimental Procedures}

The specimens used for fatigue crack growth rate measurement in the present experiment were singleedge notched, pin-loaded, with the starting notch oriented perpendicular to the rolling direction of the steel plate or in the ASTM-designated L-T orientation. ${ }^{7)}$ The configuration and dimensions of the specimen are shown in Fig. 1, which were similar to those used in the previous experiment. ${ }^{1)}$ The depth of the starting notch, which was prepared by means of electrodischarge machining, was approximately $9.0 \mathrm{~mm}$. Prior to acquisition of fatigue crack growth rate data, all the specimens were fatigue precracked in order to sharpen the starting notch to fatigue crack acuity. The fatigue precracking was conducted in ambient laboratory air of about $298 \mathrm{~K}$, using a fatigue testing machine to be described later. The precracking load employed was stepped down from the initial stage cyclic loading of $P_{\min } / P_{\max }=1765.2 \mathrm{~N} /$ $17652.0 \mathrm{~N}$ to the final one of $P_{\min } / P_{\max }=980.7 \mathrm{~N} /$ $9806.7 \mathrm{~N}$. The loading frequency used was $1.0 \mathrm{~Hz}$, under which the final precrack growth of about $0.5 \mathrm{~mm}$ in length occurred and the subsequent corrosion fatigue test was carried out. Here $P_{\min }$ and $P_{\max }$ denote the minimum and the maximum loads, respectively, in one fatigue loading cycle.

The fatigue crack growth rate test was carried out with a closed-loop, hydraulically actuated, servocontrolled mechanical testing system of $15 \mathrm{t}$ capacity, using a loading wave of tension-tension sinusoidal shape. The loading frequency employed was $1.0 \mathrm{~Hz}$ and the stress ratio, $R$, was maintained constant at $R=P_{\text {min }} / P_{\text {max }}=980.7 \mathrm{~N} / 9806.7 \mathrm{~N}=0.1$ throughout the whole test. Therefore, the increase in the cyclic stress intensity factor range, $\Delta K$, which is calculated by the following equation, ${ }^{8)}$ results only from the increase in corrosion fatigue crack length, $a$;

$$
\begin{aligned}
\Delta K= & \frac{\Delta P \sqrt{a}}{B W}\left[1.99-0.41(a / W)+18.70(a / W)^{2}\right. \\
& \left.-38.48(a / W)^{3}+53.85(a / W)^{4}\right] \quad \ldots \ldots \ldots \ldots \ldots
\end{aligned}
$$

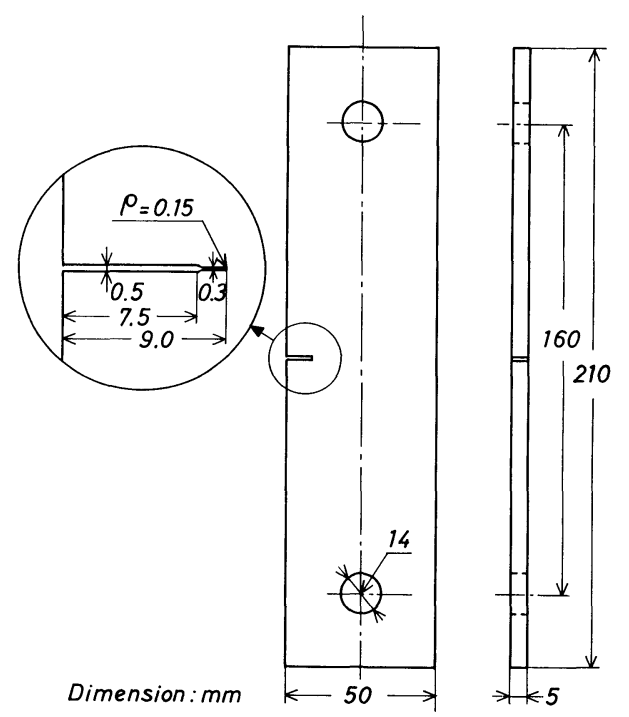

Fig. 1. Geometry of single-edge notched, pin-loaded specimen used for fatigue crack growth test. where, $\Delta P: \quad$ cyclic load range $=P_{\max }-P_{\min }$

$a$ : total crack length

$B:$ specimen thickness

$W$ : specimen width.

The total crack length, $a$, was measured with a traveling microscope to an accuracy of $\pm 0.005 \mathrm{~mm}$ by direct observation under testing conditions.

The corrosion fatigue test in the $3.5 \% \mathrm{NaCl}$ aqueous solution was conducted using a transparent plastic environment cell $110 \mathrm{~mm}$ deep $\times 110 \mathrm{~mm}$ wide $\times 80 \mathrm{~mm}$ high, which was fixed around the testing specimen, as is fully illustrated in the previous paper. ${ }^{1)}$

The temperature of the $3.5 \% \mathrm{NaCl}$ solution was regulated to an accuracy of $\pm 0.3 \mathrm{~K}$ of desired temperature in the vicinity of the specimen, by a temperature controlling system shown in Fig. 2. This system consists of a heating reservoir and a cooling one, between which the $3.5 \% \mathrm{NaCl}$ solution flows, and the desired temperature is obtained. The capacity of the solution in the reservoirs was about $70 \mathrm{dm}^{3}$. The $3.5 \% \mathrm{NaCl}$ solution at a desired temperature was continuously circulated through the environment cell from reservoirs at a flow rate of $400 \mathrm{~cm}^{3} / \mathrm{min}$. The $3.5 \% \mathrm{NaCl}$ aqueous solution was renewed for every one specimen.

An electrochemical potential was applied to the specimen during corrosion fatigue testing by means of a potentiostate device and was monitored continuously to be maintained constant at $-1050 \mathrm{mV}$ $v s$. silver/silver chloride (Ag/AgCl) reference electrode using an agar bridge. The potential was recorded together with the electric current and temperature of the solution by a $Y-t$ plotter.

Taking care of possible time-dependent phenomena in corrosion fatigue testing, these tests were continued without any change of the testing conditions until the fracture of specimen.

Reference crack growth rates were measured in ambient laboratory air of about $298 \mathrm{~K}$ room temperature and of $50 \sim 60 \%$ relative humidity, using the same cyclic loading conditions as those in the tests in $3.5 \% \mathrm{NaCl}$ solution with exception of the loading

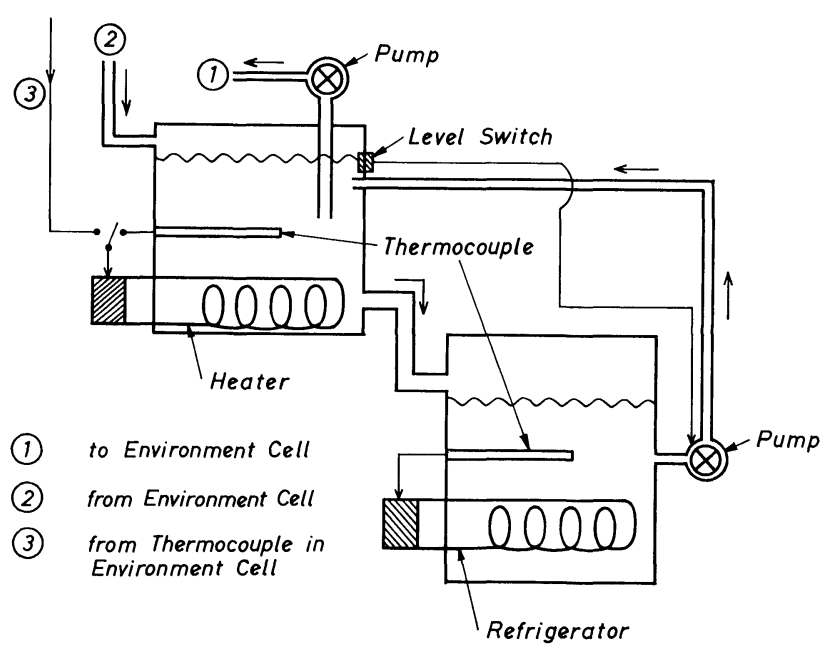

Fig. 2. Schematic drawing of the reservoirs where the temperature of $3.5 \% \mathrm{NaCl}$ aqueous solution is maintained constant. 
frequency of $20 \mathrm{~Hz}$.

The fracture surfaces of the specimens tested in $3.5 \% \mathrm{NaCl}$ solution of various temperatures and in ambient laboratory air were examined with a scanning electron microscope. As the fracture surfaces had not been severely attacked by the environment solution due to the cathodic potential application, the morphology of the fracture surfaces could be examined without any pretreatment of the specimens.

\section{Experimental Results}

\section{Fatigue Crack Growth Rate}

The experimental results obtained on the steels Nos. ST22 and ST28 are shown, respectively, in Figs. 3 and 4 as $\log -\log$ relationship between corrosion fatigue crack growth rate, $\mathrm{d} a / \mathrm{dN}$, and cyclic stress intensity factor range, $\Delta K$, at various testing temperatures. For the sake of comparison both figures contain the results obtained in ambient laboratory air. At a glance over these results obtained on two steels it can be recognized that the magnitude of the environmentally induced enhancement of fatigue crack growth increases with the increase in testing temperature of the environment solution. As shown clearly in Fig. 3 as well as Fig. 4, the dependence of corrosion fatigue crack growth rate on $\Delta K$ can not be represented by a single functional relationship, as is the case with that obtained in ambient laboratory air, but the crack growth rate curve might be divided into three distinct ranges for a given testing temperature:

(1) Range I or relatively small $\Delta K$ levels, where crack growth rate depends slightly upon testing temperature and strongly upon cyclic stress intensity factor range,

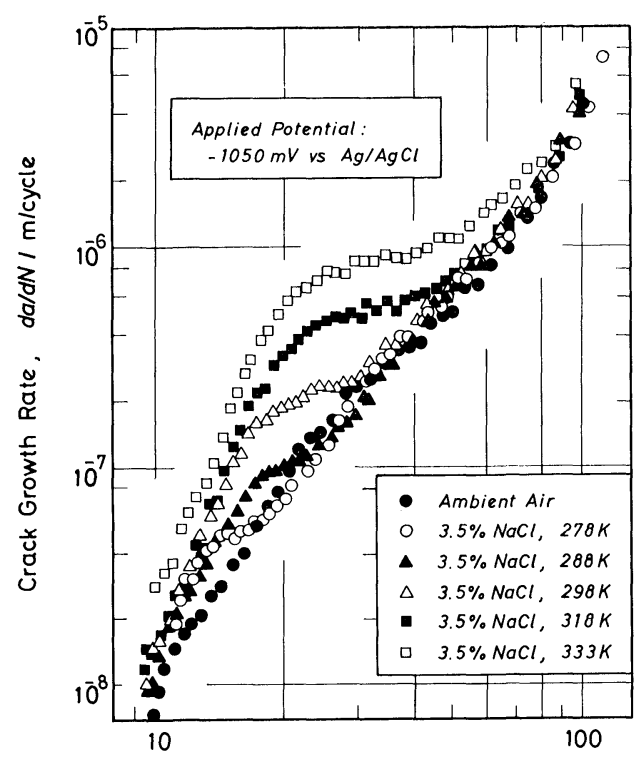

Stress Intensity Factor Range, $\Delta K \mathrm{MMPam}^{1 / 2}$

Fig. 3. Fatigue crack growth rates for the steel No. ST22 in $3.5 \% \mathrm{NaCl}$ aqueous solution at various temperatures under the applied potential of $-1050 \mathrm{mV} v$ s. $\mathrm{Ag} / \mathrm{AgCl}$ electrode.
(2) Range II or moderate $\Delta K$ levels, where crack growth rate is nearly independent of cyclic stress intensity factor range and strongly depends upon testing temperature, indicating a tendency towards a limiting rate, and

(3) Range III or relatively high $\Delta K$ levels, where the temperature dependence of crack growth rate is not detected and the results obtained in $3.5 \% \mathrm{NaCl}$ solution practically agree with those in ambient laboratory air.

It should be noted that the extent of Range II, indicating a plateau or a limiting rate on the crack growth rate curve, increases and the transition from Range I to Range II occurs at a larger cyclic stress intensity factor range with the increase in testing temperature.

\section{Fractographic Examination}

Photographs 1 to 4 show typical fracture surface appearance of the specimens (Steel No. ST22) fatigue fractured under various testing conditions. The figure appended to each photograph indicates the positions, to which the fracture surfaces correspond roughly, on the crack growth rate curves.

Photograph 1 shows the fracture surfaces of the specimens fatigue fractured at the same $\Delta K$ level in ambient laboratory air and in $3.5 \% \mathrm{NaCl}$ solution of 278 and $333 \mathrm{~K}$. Photos. $1(\mathrm{~B})$ and $1(\mathrm{C})$ represent the fracture surfaces in Range I at 278 and $333 \mathrm{~K}$, respectively. It can be clearly observed from these photographs that the corrosion fatigue fracture surfaces in Range I are characterized, independent of testing temperature, by brittle appearance with intergranular facets in contrast with those obtained in ambient laboratory air. Brittle appearance of the corrosion fatigue fracture surfaces can be observed

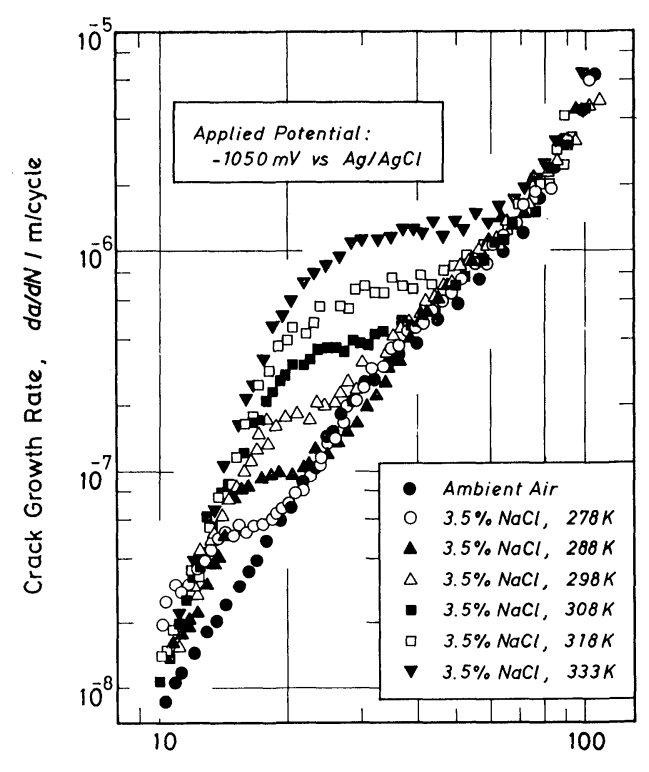

Stress Intensity Factor Range, $\Delta K / \mathrm{MPam}^{1 / 2}$

Fig. 4. Fatigue crack growth rates for the steel No. ST28 in $3.5 \% \mathrm{NaCl}$ aqueous solution at various temperatures under the applied potential of $-1050 \mathrm{mV} v s$. $\mathrm{Ag} / \mathrm{AgCl}$ electrode. 

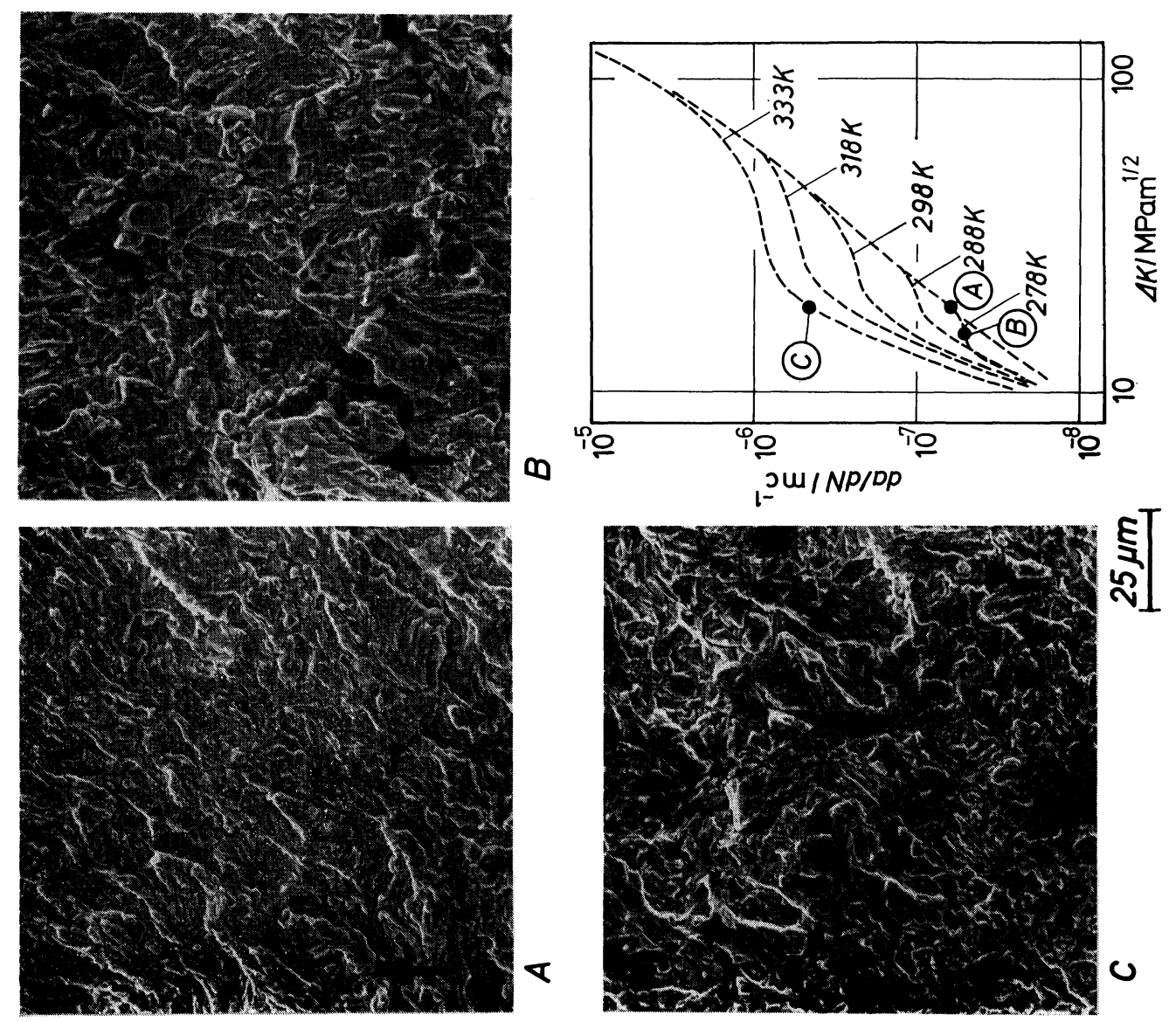

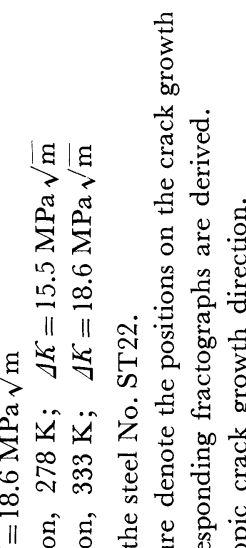

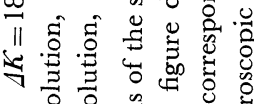

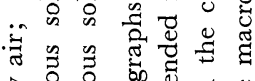

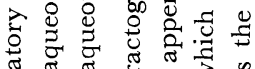

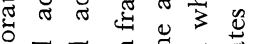

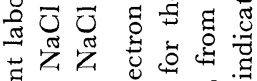

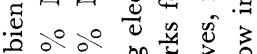

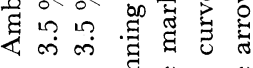

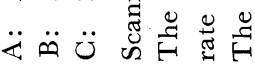
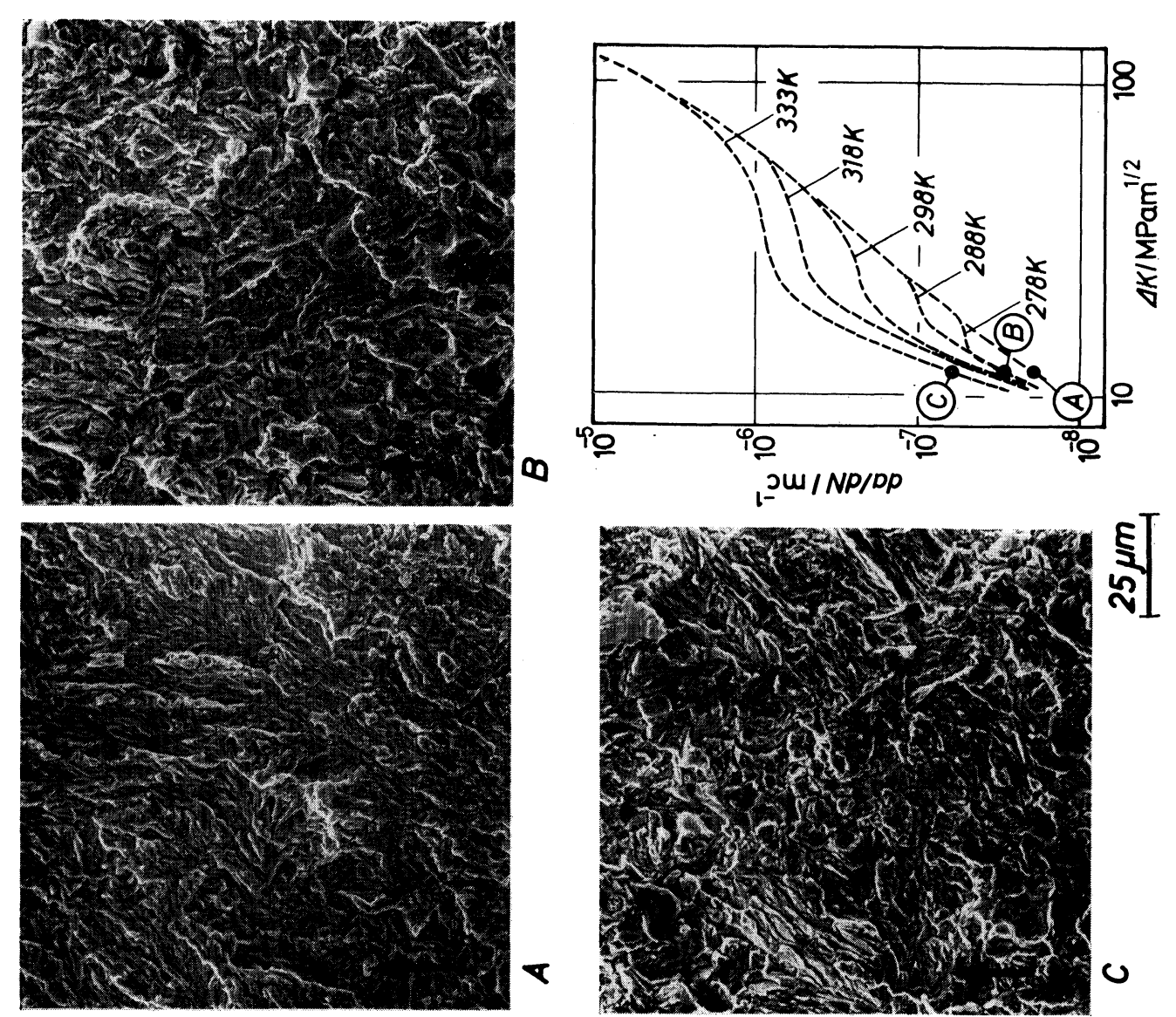

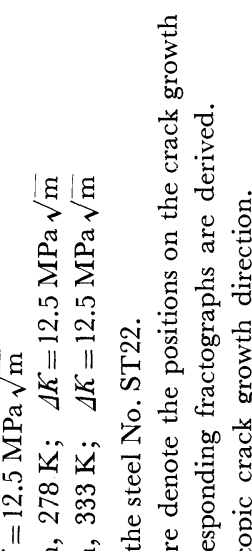

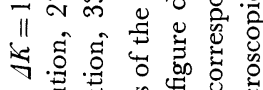

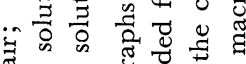

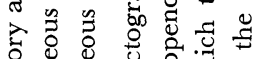

ज्ञ ज्ञ

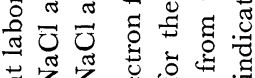

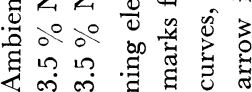

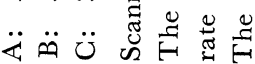



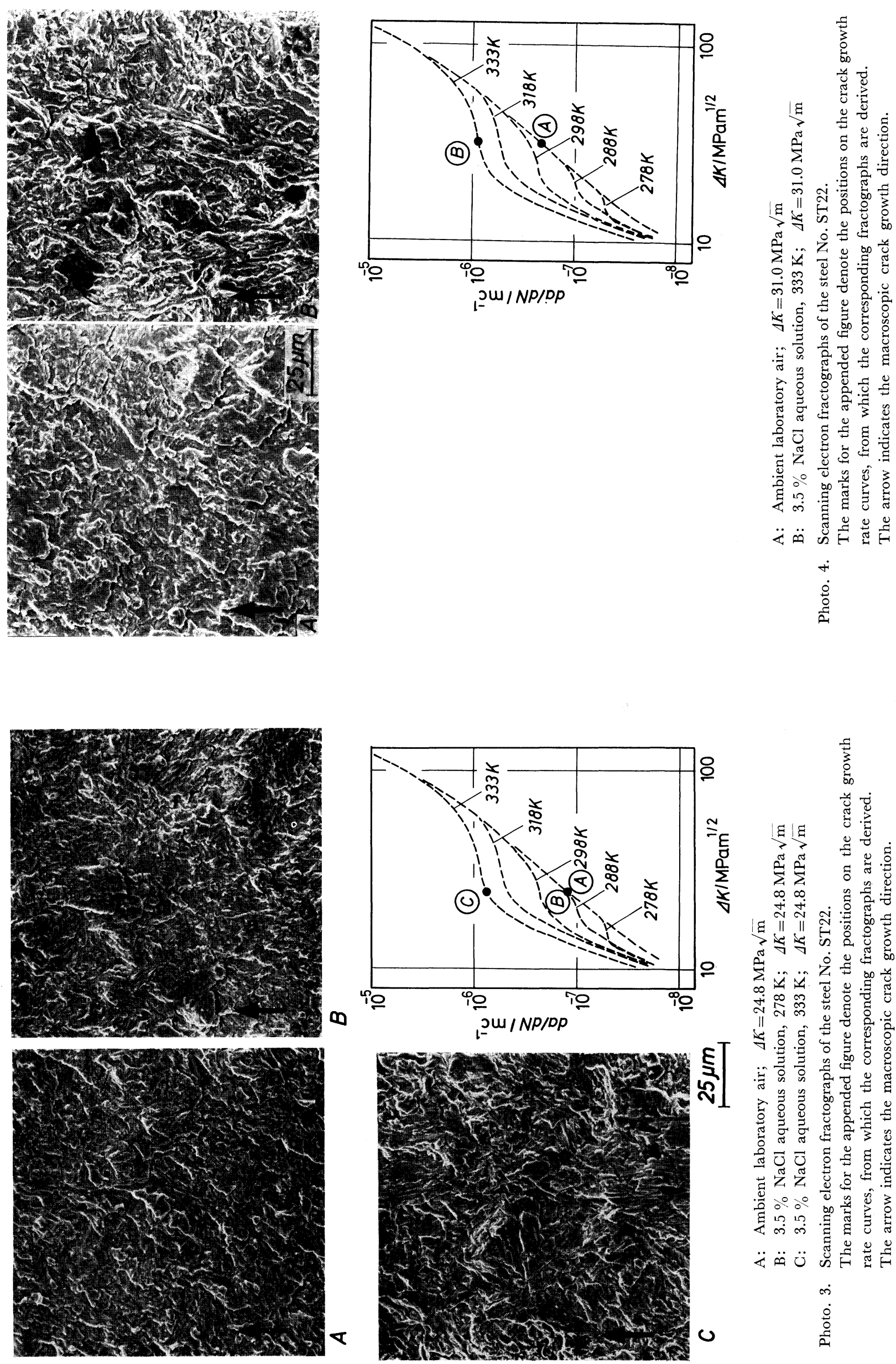

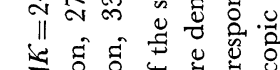

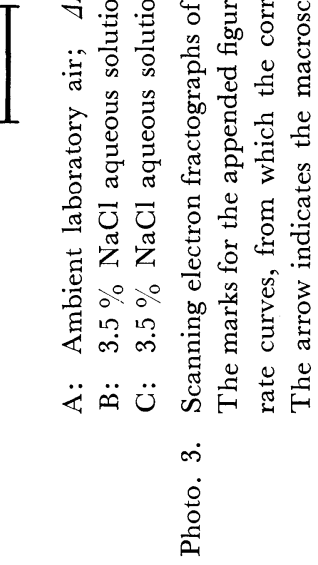


also in Range II, independent of testing temperature (see Photo. 2(B) for $278 \mathrm{~K}$ and Photo. 4(B) for $333 \mathrm{~K}$ ), while the fracture surfaces obtained in ambient laboratory air at corresponding $\Delta K$ levels exhibit transgranular facets with a portion of ductile striations and secondary cracks.

On the other hand, the corrosion fatigue fracture surfaces in Range III, where crack growth rate in $3.5 \% \mathrm{NaCl}$ solution practically coincides with that in ambient laboratory air, are of similar ductile appearance with those fatigued in ambient laboratory air, as can be confirmed by comparing Photos. 3(A) and $3(\mathrm{~B})$.

To sum up the results of fractographic examinations, the corrosion fatigue fracture surfaces in Ranges I and II are characterized by brittle appearance with intergranular facets, while those in Range III exhibit transgranular facets of ductile appearance, which can be compared well with the fracture surfaces obtained in ambient laboratory air at corresponding $\Delta K$ levels. The above-mentioned arguments are valid also for the fracture surface of the steel No. ST28. This means that the extent of the range, where corrosion fatigue crack growth occurs in the brittle manner, increases with increase in testing temperature.

\section{Discussion}

The experimental results presented in the preceding section on the relationship between corrosion fatigue crack growth rate and cyclic stress intensity factor range apparently have many qualitative similarities with those on the relationship between stress corrosion cracking and stress intensity factor for high strength steels. Moreover, the Range II type corrosion fatigue crack growth behavior has been pointed out ${ }^{9)}$ to take place in the corrosion fatigue crack growth above the threshold stress intensity factor for stress corrosion cracking, $K_{\text {Isce }}$. It can, therefore, be assumed that the Range II type corrosion fatigue crack growth occurs typically in high strength steels, which have potentially relatively low threshold value, $K_{I s c c}$.

It can be recognized from the results shown in Fig. 3 as well as Fig. 4 that a small temperature change causes large variation in corrosion fatigue crack growth rate, particularly, in Range II. Variation of $1 \mathrm{~K}$ around room temperature can cause a corrosion fatigue crack growth rate change of roughly $10 \%$. These results denote the necessity of careful control of environment solution, when high strength steels, which have a tendency to exhibit Range II crack growth behavior, are used for corrosion fatigue testing. In the following, therefore, crack growth behavior in Range II will be discussed in detail in connection with testing temperature.

The existence of Range II or the rate limiting crack growth stage is observed at all testing temperatures in the present experiment. This observation is physically significant because it suggests that the crack growth in this range is controlled by a certain rate limiting process. ${ }^{2)}$ The results shown in Figs. 3 and 4 indicate a strong effect of testing temperature on Range II crack growth rate, as already men- tioned. These data can be replotted, as represented in Fig. 5 as well as Fig. 6, and expressed by the following equation;

$$
(\mathrm{d} a / \mathrm{dN})_{\text {Range II }} \propto \exp \left(-E_{a} / R T\right)
$$

where, $E_{a}$ : apparent activation energy of the rate limiting process for the Range II crack growth

$R:$ gas constant

$T$ : temperature.

The apparent activation energy, $E_{a}$, is given by the slope of the line approximating the relation between $\mathrm{d} a / \mathrm{dN}$ and $1 / T$ as shown in Figs. 5 and 6 . It is approximately $40.0 \mathrm{~kJ} / \mathrm{mole}$ for both experimented steels.

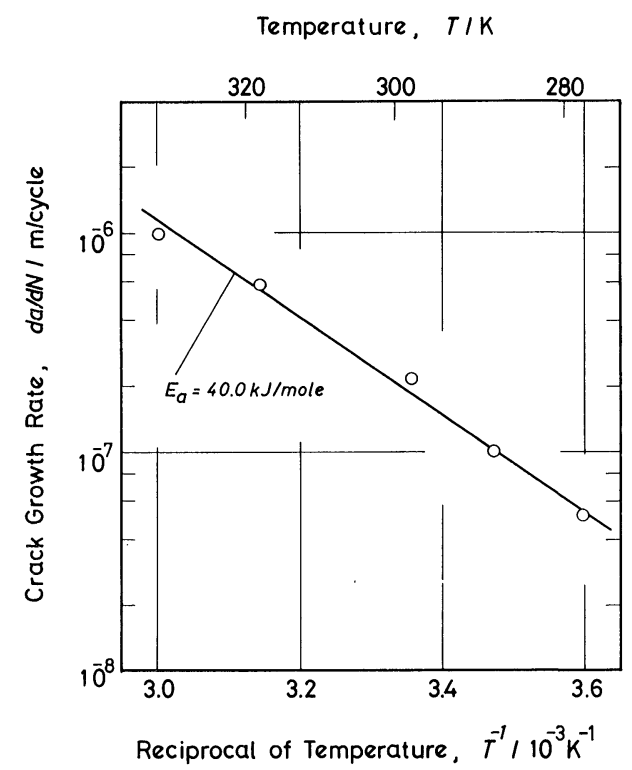

Fig. 5. Grack growth rate in Range II as a function of the reciprocal of testing temperature for the steel No. ST22.

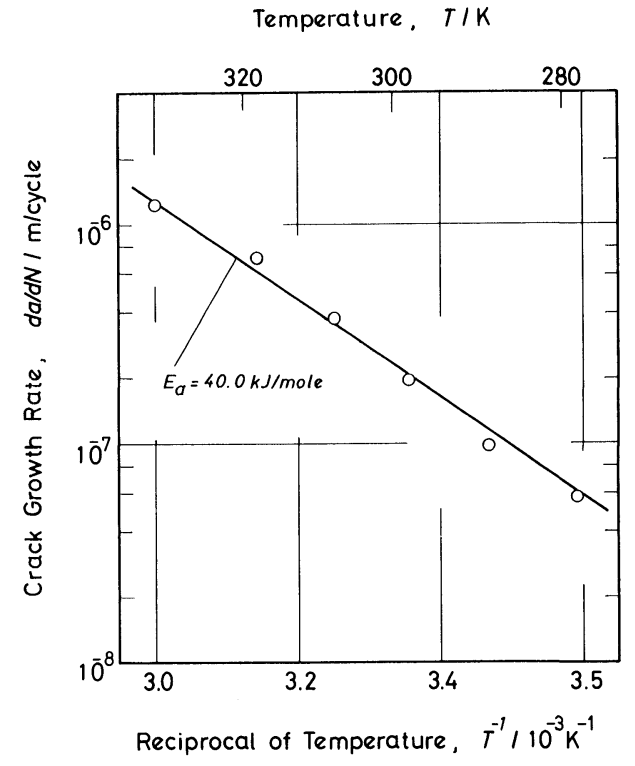

Fig. 6. Crack growth rate in Range II as a function of the reciprocal of testing temperature for the steel No. ST28. 
As discussed in the previous report, ${ }^{1)}$ in synthetic seawater and probably also in natural seawater the application of cathodic electrochemical potential to a specimen can bring about two competing effects on corrosion fatigue crack growth rate. They are hydrogen evolution and calcareous deposit formation. The calcareous deposit formation, however, can be excluded from consideration in the present experiment, because $3.5 \% \mathrm{NaCl}$ solution was used as an environment solution, while hydrogen released under the cathodic electrochemical potential application can diffuse into specimen and contribute to the fatigue crack growth enhancement.

It has been pointed out ${ }^{10)}$ that the apparent activation energy for diffusion of hydrogen in iron and steel at temperatures below $423 \sim 473 \mathrm{~K}$ is in the range of $25.0 \sim 40.0 \mathrm{~kJ} / \mathrm{mole}$ and hydrogen diffusion above these temperatures is the one of lattice hydrogen with apparent activation energy of about $4.0 \sim 10.5 \mathrm{~kJ} / \mathrm{mole}$. It has been understood ${ }^{11,12)}$ that the former activation energy is concerned with the release of trapped hydrogen, since at temperatures below $423 \sim 473 \mathrm{~K}$ hydrogen collects in trap sites, such as voids, microcracks, grain boundaries, precipitates, etc. Thus, the diffusion rate at ambient temperature is not controlled by lattice diffusion of hydrogen. Table 3 lists apparent activation energies of hydrogen diffusion for several materials at ambient temperature. By comparing these with the apparent activation energy for the Range II crack growth obtained in the present experiment, it can be reasonably concluded that both of them agree fairly well each other and that the Range II crack growth rate appears to be controlled by apparent hydrogen diffusion.

The above-mentioned results can be compared well with those published on the so-called State II stress corrosion cracking in aqueous solution environments, where the rate of cracking is independent of applied stress intensity factor, indicating a tendency toward a limiting value. It has been reported ${ }^{2,5)}$ that the rate of stress corrosion cracking in this stage appears to be controlled by hydrogen diffusion based on correspondence between the observed activation energy and that of apparent hydrogen diffusion in steel, the value of which is nearly equal to that obtained in the present experiment.

The brittle fracture surface appearance with intergranular facets in Range II is consistent with the corrosion fatigue crack growth mechanism in which hydrogen diffusion in steel plays an important role. The wider extent of Range II, namely the higher $\Delta K$ level at which the transition from Range II to
Range III with the increase in testing temperature appears to be related to higher hydrogen diffusion rate, that is, the larger critical hydrogen embrittlement region at the crack tip vicinity. ${ }^{18)}$

The crack driving force in Range III is essentially the mechanical one, independent of environment in which the fatigue crack growth takes place, because the cyclic stress intensity factor range, $\Delta K$, is large enough and crack growth in this range is too rapid to be influenced by environmental effects. In consequence the crack growth rate as well as fracture characteristics of ductile transgranular facets obtained in $3.5 \% \mathrm{NaCl}$ solution is practically identical with that in ambient laboratory air.

On the contrary, it is not necessarily surprising that corrosion fatigue crack growth in Range I is accelerated due to environmental effects, because the cyclic stress intensity factor range, $\Delta K$, and therefore the crack growth rate are relatively small in this range. The fact that the Range I crack growth is dependent on the applied stress intensity factor range, $\Delta K$, as well as environmental solution temperature suggests the possibility that the crack growth in this range is also accelerated by hydrogen released under the cathodic electrochemical potential application of $-1050 \mathrm{mV}$ vs. $\mathrm{Ag} / \mathrm{AgCl}$ electrode as is the case in Range II. This estimation on the contribution of hydrogen to the crack growth acceleration in Range I is justified also by the experimental fact that the corrosion fatigue fracture surface in Range $I$ is characterized by brittle appearance with intergranular facets. But as expected from the results shown in Figs. 3 and 4, the activation energy for Range I crack growth is not equal to that for hydrogen diffusion and moreover dependent on the cyclic stress intensity factor range, $\Delta K$. This means that the Range I corrosion fatigue crack growth rate is not controlled by the hydrogen diffusion. The mechanism of the acceleration of fatigue crack growth in this range cannot be discussed in detail on the basis of the present experimental results.

\section{Concluding Remarks}

Corrosion fatigue crack growth rates of two experimental high strength, low-alloy Ni-Cr-Mo steels were investigated as a function of $3.5 \% \mathrm{NaCl}$ aqueous solution temperature between $278 \mathrm{~K}$ and $333 \mathrm{~K}$. Corrosion fatigue experiments were carried out using a constant tension-tension cyclic loading amplitude with a frequency of $1.0 \mathrm{~Hz}$ under the electrochemical potential of $-1050 \mathrm{mV}$ vs. $\mathrm{Ag} / \mathrm{AgCl}$ reference electrode controlled with a potentiostat device. The

Table 3. Apparent activation energy for hydrogen diffusion in steels.

\begin{tabular}{l|l|c|c}
\multicolumn{1}{c|}{ Material } & \multicolumn{1}{|c|}{ Testing Method } & $E_{a}(\mathrm{~kJ} / \mathrm{mole})$ & \multicolumn{1}{c}{ Ref. } \\
\hline AISI4340 & Diffusion of electrolytic hydrogen & 38.6 & W. Beck et al. $(1966)^{13)}$ \\
Low carbon steel & Effusion process of thermally charged hydrogen & $35.6 \sim 39.6$ & G. M. Evans et al. $(1969)^{14)}$ \\
Ni-Cr-Mo steel & Evolution of thermally charged hydrogen & $32.6 \pm 6.7$ & F. R. Coe et al. $(1966)^{15)}$ \\
Pure $\alpha$-iron & Evolution rate of hydrogen & $32.7 \pm 6.7$ & E. W. Johnson et al. $(1960)^{16)}$ \\
Ni-Cr-Mo steel & Loss of hydrogen present naturally & 52.0 & J. D. Hobson $(1958)^{17)}$
\end{tabular}


results obtained in the present experiment are summarized as follows:

(1) For all the testing temperatures of $3.5 \% \mathrm{NaCl}$ aqueous solution the corrosion fatigue crack growth rate, $\mathrm{d} a / \mathrm{dN}$, curve as a function of cyclic stress intensity factor range, $\Delta K$, can be divided into three distinct ranges in the present experiment.

(2) In Range I, which corresponds to relatively small $\Delta K$ region, the crack growth rate depends strongly upon $\Delta K$ and slightly upon environment solution temperature. The fracture surface obtained in this range of crack growth is characterized by brittle appearance with intergranular facets, independent of testing temperature. The detailed mechanism of the crack growth acceleration in Range I could not be established, although the contribution of hydrogen released under the electrochemical potential application of $-1050 \mathrm{mV}$ vs. $\mathrm{Ag} / \mathrm{AgCl}$ electrode could be pointed out.

(3) In Range II, which corresponds to moderate $\Delta K$ region, the crack growth rate depends strongly upon testing temperature but not upon $\Delta K$. Crack growth in this range is thermally activated with an apparent activation energy of $40.0 \mathrm{~kJ} /$ mole and can, therefore, be concluded as controlled by apparent hydrogen diffusion. This argument can be justified by fractographic examination.

(4) In Range III, which corresponds to relatively large $\Delta K$ region, the corrosion fatigue crack growth rate curves coincide with those obtained in ambient laboratory air. The corrosion fatigue fracture surface indicates quite similar appearance to that in ambient laboratory air. The corrosion fatigue crack growth in this range takes place without any essential contribution from environment, as the cyclic stress intensity factor range and thus the intrinsic crack growth rate in this range are very large.

\section{Acknowledgements}

The author wishes to thank Prof. Dr. R. Helms and Dr. B. Isecke, Federal Institute for Materials Testing, Berlin, FRG, as well as Dr. E. Furubayashi and many other members of the High Strength Materials Division, National Research Institute for Metals, Japan, for helpful discussion. He is also indebted to the late Dr. I. Uchiyama, Deputy Director-General of NRIM, for his invaluable suggestions and encouragement.

\section{REFERENCES}

1) T. Saito and I. Uchiyama: Trans. ISIJ, 22 (1982), 586.

2) J. D. Landes and R. P. Wei: Int'l J. Fracture, 9 (1973), 277.

3) W. A. Van der Sluys: Engineering Fracture Mechanies, 1 (1969), 447.

4) G. L. Hanna, A. R. Troiano and E. A. Steigerwald: $A S M$, 57 (1964), 658.

5) H. H. Johnson: Fundamental Aspects of Stress Corrosion Cracking, ed. by R. W. Staehle, A. J. Forty and D. VanRooyen, NACE, Houston, (1969), 439.

6) R. H. Smith, D. E. Piper and F. R. Downey: Engineering Fracture Mechanies, 1 (1969), 123.

7) ASTM Designation E399-74, (1977).

8) W. F. Brown, Jr. and J. E. Srawley: Plane Strain Crack Toughness Testing of High Strength Metallic Materials, ASTM Special Tech. Publ., 410, ASTM, Philadelphia, (1969).

9) A. J. McEvily and R. P. Wei: Corrosion Fatigue, Chemistry, Mechanism and Microstructure, ed. by O. F. Devereux, A. J. McEvily and R.W. Staehle, NAGE, Houston, (1972), 381.

10) K. Ono and L. A. Rosales: Trans. AIME, 242 (1968), 244.

11) C. R. Frank: J. Appl. Phys., 29 (1958), 1269.

12) K. Farrell: JISI, 203 (1965), 71.

13) W. Beck, J. O'M. Bockris, J. McBreen and L. Nanis: Proc. Roy. Soc., A290 (1966), 221.

14) G. M. Evans and E. C. Rollason: JISI, 207 (1969), 1484.

15) F. R. Coe and J. Moreton: JISI, 204 (1966), 366.

16) E. W. Johnson and M. L. Hill : Trans. AIME, 218 (1960), 1104.

17) J. D. Hobson: JISI, 189 (1958), 315.

18) St. John and W. W. Gerberich: Met. Trans., 4 (1973), 589 . 